\title{
Effects of Speeds, Materials, and Tool Rake Angles on Metallic Particle Emission During Orthogonal Cutting
}

Riad Khettabi, Victor Songmene, and Jacques Masounave

(Submitted June 2, 2008; in revised form August 25, 2009)

\begin{abstract}
Dry high speed machining has been proposed as a viable and cost-effective process in metal cutting industries. However, it produces fine and ultra-fine metallic particles, also referred to as dust, which can be harmful to the machine-tool operator. The risk associated with exposure to metallic particles increases as the particle size decreases. For machining processes, little data exist on the size and distribution of dust generated during the shaping of materials. In order to reduce or eliminate the generation of these particles, it is necessary to understand how and under which conditions they are formed, as well as to be able to make predictions. In this study, the effects exerted by tool geometry, material, and machining parameters on dust emission were studied experimentally in order to understand the mechanisms of dust generation and to develop a predictive model. The particle sizes studied include the PM2.5 (particles with aerodynamique diameter below $2.5 \mu \mathrm{m}$ ) and a distribution of nanoparticles varying in size from $10 \mathrm{~nm}$ to $10 \mu \mathrm{m}$. Using dry machining and reducing the amount of dust generated should improve the air quality in machine shops in addition to helping protect the environment.
\end{abstract}

Keywords air quality, dry turning, fine particles, nanoparticles, PM2.5, tool rake angle

\section{Introduction}

The process performance of modern metalworking is not limited to criteria such as productivity, precision, surface quality, or cycle time. The protection of operators and the environment has become an additional machining process performance indicator which must be taken into consideration.

Generally, all machining processes generate aerosols in solid or liquid form, with both forms being harmful both to operator health and to the environment (Ref 1, 2). Solid aerosols are generated from part materials during dry and wet machining, while liquid aerosols are produced when cutting fluids are used (Ref 3-5). The primary mechanisms responsible for wet aerosol production include fluid impact on the workpiece and evaporation (Ref 6-11). Cutting fluids are not only toxic (Ref 12, 13), but are costly as well, given the price of initial purchase and the cost of treating used fluids.

Liquid aerosol produced from cutting fluids can be eliminated through dry machining, which however, also presents the problem of solid aerosol production. Eliminating cutting fluids reduces manufacturing costs and some of the aerosols generated. In fact, it has been determined that wet machining generates more fine airborne particles than does dry machining (Ref 14). At high cutting speeds in dry machining, the particle

Riad Khettabi, Victor Songmene, and Jacques Masounave, ETS, Mechanical Engineering, University of Quebec, 1100 rue Notre-dame Ouest, Montreal, QC H3C 1K3, Canada. Contact e-mail: victor. songmene@etsmtl.ca. size produced is between 1 and $4 \mu \mathrm{m}$, while in wet machining, the size is less than $1 \mu \mathrm{m}$ (Ref 14).

In 1999, a World Health Organization working committee on airborne particles pointed out the need for research into particle generation during the manufacturing process, in order to allow regulations and controls to be brought in with respect to the production of airborne particles (Ref 15).

In the USA, regulations of the Occupational Safety and Health Administration (OSHA) stipulate that worker exposure to fine dust and PM2.5 during an 8-h work shift must not exceed $15 \mathrm{mg} / \mathrm{m}^{3}$ (Ref 14). Regulations (DIN IN 482, 1991) are even more severe in Germany, where average fine particle emission must not exceed $6 \mathrm{mg} / \mathrm{m}^{3}$ at any work station (Ref 16).

Environmental regulations governing aerosol emissions have traditionally been very strict. For example, in 2005, the OSHA called for a 50-fold decrease from the standards in effect at the time for the PEL of "hexavalent chromium" during the metal finishing process of $1 \mu \mathrm{g} / \mathrm{m}^{3}$ (Ref 17). In 1970, the OSHA, in setting the permissible exposure level (PEL), limited the concentration of cutting fluid mist in the industrial environment to $5 \mathrm{mg} / \mathrm{m}^{3}$, with a view to protecting operators, and then, in 1998, proposed that the level be further reduced to $0.5 \mathrm{mg} / \mathrm{m}^{3}$ (Ref 18 ).

The major problem with dry machining is shortened tool life. Since cutting fluids are used to lubricate the operation and/or to cool the workpiece and the cutting tool, dry machining must therefore be performed with thermally stable tools. Carbide tools coated with $\mathrm{TiN}, \mathrm{TiC}$, or $\mathrm{Al}_{2} \mathrm{O}_{3}$ are recommended for use in dry cutting (Ref 19). If dry machining is not possible, a minimum quantity of lubricant (MQL) could be used to ensure a reasonable tool life. While the MQL method is an ecologically and economically beneficial machining technique (Ref 20-26), MQL is however still susceptible to the generation of wet and dry aerosols, in addition to needing additional equipment. For dry machining to become a viable alternative, it is therefore advisable that the focus be directed to the dry dust problem. 
Dry aerosols generated during the metal cutting process have been found to be dependent on the workpiece material and on its condition, as well as on operating parameters (Ref 14, 27-29). Most of the works cited here (Ref 27-29) were performed only for drilling processes. Khettabi et al. (Ref 30) confirmed these results while turning steels and aluminum alloys. They also found that the tool lead angle affects chip formation, and the amount of metallic particles generated. The tool geometry, and the rake angle in particular, affects most of the process performance indicators present in metal cutting: cutting forces, temperature, chip formation, surface finish, tool life, and deformations.

During machining with larger negative angles, Ohbuchi and Obikawa (Ref 31) noticed that a stagnant region was present on the rake face of the tool, close to its tip. The presence of this zone modifies the tool geometry (rake angle and nose radius) and therefore influences chip formation. The stagnation zone is very similar to a built-up edge (BUE), except that it has a more stable structure (Ref 32). Ohbuchi and Obikawa (Ref 31) also proved the existence of a critical speed and a critical undeformed chip thickness for better chip formation and efficient material removal, and found that these critical values were affected by the rake angle. The chip formed and flew unconditionally when the rake angle was $-15^{\circ}$ or higher, while for a tool with rake angles between $-15^{\circ}$ and $-45^{\circ}$, the critical speed increased as the rake angle decreased.

The use of negative rake angles results in a large tool-chip contact area and higher volume of chip, thus leading to increased cutting forces and heat generation (Ref 33). The rake angle in fact modifies the chip formation, the shear angle, and the friction, and these indirect parameters can also have an impact on dust emission.

Fang (Ref 32) studied tool-chip friction occurring during machining with a large negative rake angle, and found that a negative tool rake angle increases the cutting force ratio, the chip thickness ratio, the tool-chip friction angle, the slip-line angle, the apex angle of the stagnation zone, and the coefficient of friction, but also decreases the shear-plane angle. These effects are the opposite of those encountered when a tool with a positive rake angle is used.

Very little is known about the effect of the tool rake angle and the interaction between the tool geometry, the workpiece materials, and the cutting parameters, on the generation of metallic particles during machining.

In this work, an extended study is carried out to identify the effects of the tool rake angle, chip segmentation density, materials, and cutting speed on dust emission during dry orthogonal cutting. The results will assist in the development of strategies for reducing fine and ultrafine dust emission and for predicting dust emission. Orthogonal cutting allows 2D modeling, which in turn simplifies the cutting process. Modeling particle emission seen during the cutting process requires an understanding of the mechanisms involved as well as the behavior of the material. Friction, shearing and deformation all come into play during machining operation. In predicting particle emission, it is difficult to quantify friction and plastic deformation during oblique machining. A first paper (Ref 30) studied particle emission occurring during oblique cutting (which is commonly used in industry), whereas one of the main goals of this work is to study orthogonal cutting in order not only to understand, but also to go onto model and find possible correlations between orthogonal and oblique processes.

\section{Experimental Method}

Different measuring instruments were used depending on the size of the particles studied. A laser photometer (TSI8520 Dustrack), an aerosol particle sizer (APS), and a scanning mobility particle sizer (SMPS) from TSI instruments were used to quantify the particles produced. For particle concentration, especially for those with an aerodynamic diameter below $2.5 \mu \mathrm{m}$, the laser photometer (Dustrack) was used. The Dustrack was connected to the dust recovery enclosure by a suction pipe (tube in Fig. 1). The air flow $(1.7 \mathrm{~L} / \mathrm{min}$ ) passes through an impactor which allows only particles with an aerodynamic diameter lower than $2.5 \mu \mathrm{m}$ to pass through to the measuring device (Fig. 1). The APS, which measures the aerodynamic size distribution range from 0.5 to $20 \mu \mathrm{m}$, was used for particle size distribution. The APS spectrometer accelerates the aerosol sampled through an accelerating orifice. The particle aerodynamic size determines its rate of acceleration, with smaller particles accelerating more quickly due to decreased inertia. After this step, the particles cross through two partially overlapping laser beams in the detection area. Using light scattering at $90^{\circ}$, the light is collected and focused onto an avalanche photodetector (APD), which then converts the light pulses into electrical pulses. The use of two partially overlapping laser beams results in each particle generating a single two-crested signal. Peak-to-peak time-of-flight is measured with a 4-ns resolution for aerodynamic sizing. It has been found through a comparative study between the APS spectrometer and two other aerosol spectrometers that the APS results are similar to those obtained with the other spectrometers for mono-dispersed particles (Ref 34). However, for particles smaller than $0.7 \mu \mathrm{m}$, the APS system is less efficient than the portable aerosol spectrometer (PAS) (Ref 34). To enhance the efficiency and the accuracy of the results, the APS was coupled with a SMPS to study the particle distribution during orthogonal turning. The SMPS spectrometer measures the aerosol size distribution range from 2.5 to $1000 \mathrm{~nm}$ using an electrical mobility detection technique. It uses a bipolar charger in the electrostatic classifier to charge the particles over a known charge distribution. The particles are then classified based on their ability to pass through an electrical field and are counted with a condensation particle counter (CPC). A computer

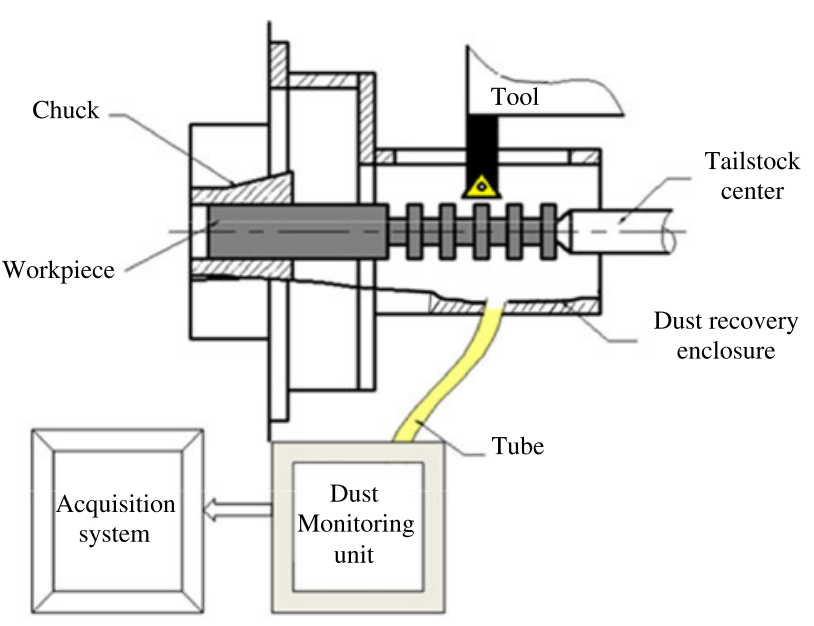

Fig. 1 Experimental setup 


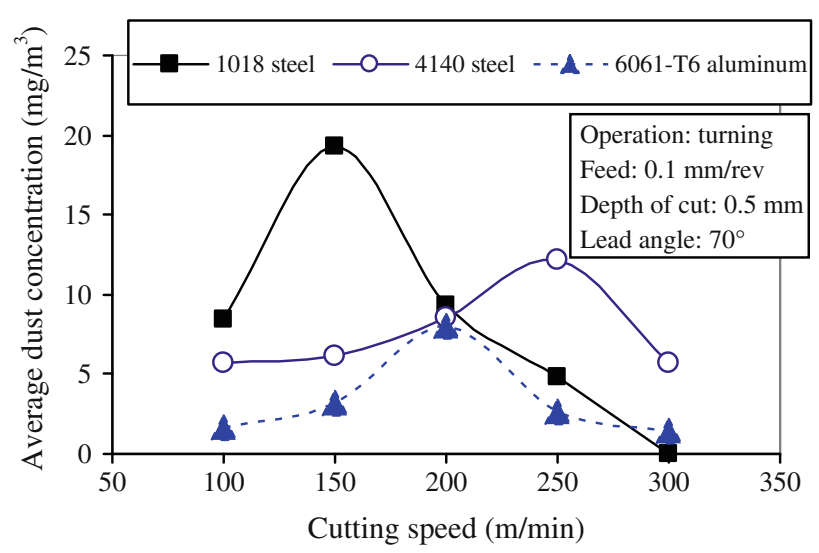

Fig. 2 Average dust concentration (PM2.5) as a function of cutting speed when turning steels and 6061-T6 aluminum

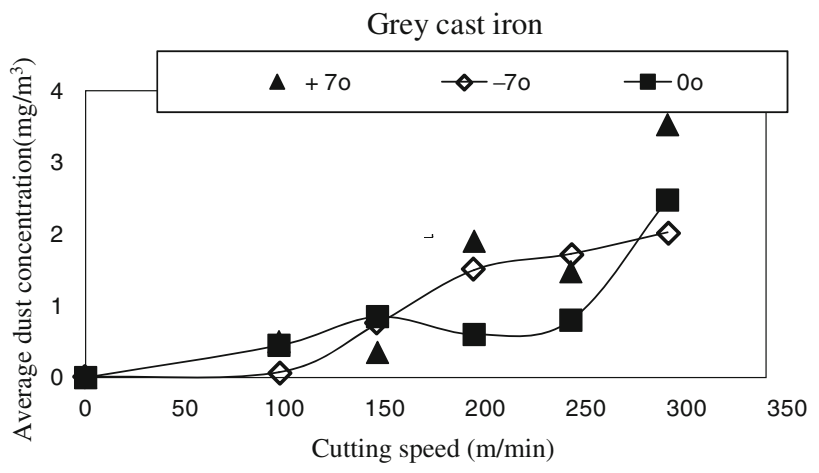

Fig. 3 Dust Unit as a function (PM2.5) of cutting speed during turning of gray cast iron

Table 1 Conditions and parameters used during the test

\begin{tabular}{ll}
\hline Operation & \multicolumn{1}{c}{ Orthogonal cutting } \\
\hline Feed rate, $\mathrm{mm} / \mathrm{rev}$ & 0.203 \\
Cutting speed, $\mathrm{m} / \mathrm{min}$ & $0-300$ \\
Tool material & Uncoated carbide \\
Rake angles, & $-7,0,+7$ \\
Lubricant and coolant & None \\
Workpiece materials & Aluminum alloy 6061-T6 \\
& AISI 1018 steel, cold-rolled \\
& AISI 4140 steel, quenched, and tempered \\
& Gray cast iron \\
\hline
\end{tabular}

equipped with an appropriate data acquisition (TSI Aerosol Instrument Manager ${ }^{\circledR}$ software) and analysis system was connected to the measuring device. The TSI Aerosol Instrument Manager software is a program that controls instruments operation, collects and corrects the data for the number of charges and for the impactor and CPC lower-detection counting efficiency. It also provides file-management from both APS and SMPS. Data can be weighted by number concentration, diameter, surface area, volume, or mass. It also provides comprehensive statistical analysis for the entire distribution or specific size ranges selected.

The cutting conditions used for the experiments are summarized in Table 1.

\section{Results and Discussions}

It was found that the quantity of dust generated during the machining process depends on the cutting tool geometry, the workpiece materials and the cutting parameters used (Ref 27-30, 35). Therefore, it is necessary to analyse the effect of these factors on dust emission.

\subsection{Effect of Tool Geometry: Lead and Rake Angles}

The tool geometry affects many aspects of the metal cutting process: it has a direct effect on the shearing action, on the deformation, on the cutting forces, on the temperature and the surface finish, and on chip formation. It is expected that the tool geometry also influences dust emission.

In an oblique cutting process, the chip shape is affected by the tool lead angle. However, it was found that the lead angle has no significant influence on the chip segmentation mode (Ref 30). Low and large tool lead angles produce wide chips, but when the lead angle approaches $90^{\circ}$, the chip becomes thinner. Experimental results (Ref 30) showed that the dust emission, evaluated by the dust unit $(D u)$, is very low when a $90^{\circ}$ tool lead angle is used.

In orthogonal cutting, the tool geometry includes the clearance angle, nose radius, and the rake angle. The clearance angle is chosen so as to ensure that there is less friction between the tool and the workpiece. The rake angle affects the shear angle, the chip formation, flow and morphology, the contact length tool-chip, the cutting forces, the tool life, the temperature involved in the cutting, the chip compression ratio, and the chip segmentation frequency, and consequently, is expected to influence the dust emissions.

The tool rake angle can be either positive or negative. While cutting forces do decrease with an increase in rake angle, the fact however, is that a tool with a very high positive rake angle lacks strength: larger rake angles reduce the rate of heat dissipation along the tool, while negative rake angle tools have increased strength and increased heat dissipation (Ref 36). Most of the effects of the tool rake angle, such as those on tool life, chip form, and surface finish, also depend on the cutting speed used.

Typical rake angles recommended for roughing operations with carbide inserts and solid carbide tools are $+3.5^{\circ}$ for mild steel, brass, and bronze, $0^{\circ}$ for cast iron and cast brass, and $+13^{\circ}$ for light alloys (Ref 37).

Experimental tests conducted on the orthogonal cutting of steels, gray cast iron, and aluminum alloys, with different rake angles, have shown a significant increase in dust emission when a positive rake angle is used (Fig. 4-7). For all tested materials, the tendency is the same, but with ductile materials such as steels and aluminum alloys (Fig. 4-6), the particle emissions are proportionally very high compared to the particle emissions of brittle materials such as gray cast iron (Fig. 7). Indeed in the case of gray cast iron machined at cutting speeds of 200 and $250 \mathrm{~m} / \mathrm{min}$ (Fig. 7), the particle emissions are very low when the tool rake angle is null. The deformation and dust emission behavior of brittle materials is different from that of ductile materials: in the case of ductile materials, the chip is formed by brittle crack instead of plastic deformation, whereas with ductile materials, dust emission is controlled by the porosity density and the brittle crack occurring during chip formation. The high level of deformation and the difficulty of chip evacuation seen with negative rake angles can generate a small 
AISI 4140 Steel

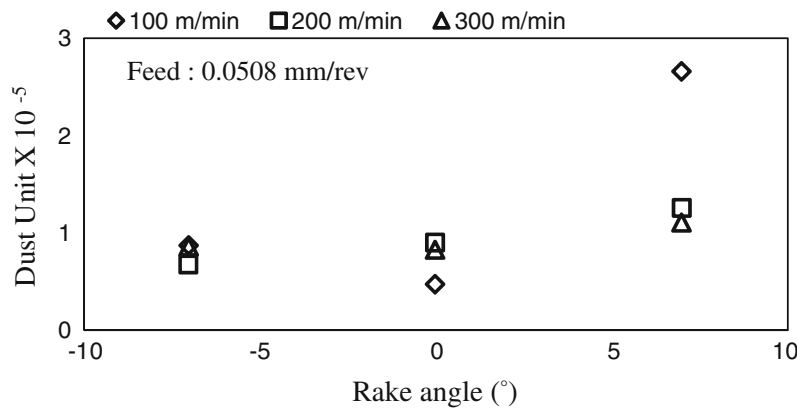

Fig. 4 Dust Unit (PM2.5) as a function of tool rake angle and cutting speeds during turning of 4140 Steel

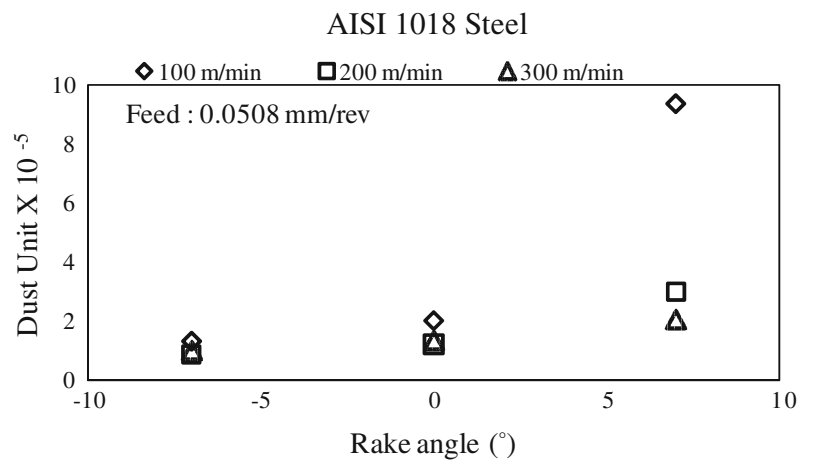

Fig. 5 Dust Unit (PM2.5) as a function of tool rake angle and cutting speeds during turning of 1018 Steel

increase in dust emission in some cases. To reduce the dust emission, negative or null rake tool angles are recommended. In the case of negative rake angles, the cutting forces and the deformation are higher than with a positive rake angle, thus making a null or a low rake angle more advantageous.

\subsection{Effect of Cutting Speed}

Arumugam et al. (Ref 35) studied dust mass concentration during machining and found that the cutting speed is the most influential of all the cutting parameters (feed, speed, and depth of cut), and that the concentration decreases as the speed is increased.

Songmene et al. (Ref 28, 29) found two different zones (I and III) corresponding to low and high cutting ranges, respectively, in which the dust emission is low, with high dust emissions seen between the two zones. This tendency was confirmed by Khettabi et al. (Ref 30) in the turning of aluminum alloys and steels. That result was also confirmed in this work during the dry turning of aluminum alloys and steel materials (Fig. 2). Given these results, a two-level factorial design, such as the one used by Arumugam et al. (Ref 35), is not appropriate for studying the effects of the cutting speed on dust emission. Such a design strategy fails to recognize quadratic effects, and a composite or a three-level factorial design should be used instead. In this work, a one-factor-at-atime type design with three levels of rake angle, four levels of materials and five levels of cutting speed was used, and the experiments were repeated three times.

Machining in zone I (low cutting speeds) is not recommended because productivity would be reduced. In zone III
6061-T6 aluminum alloy

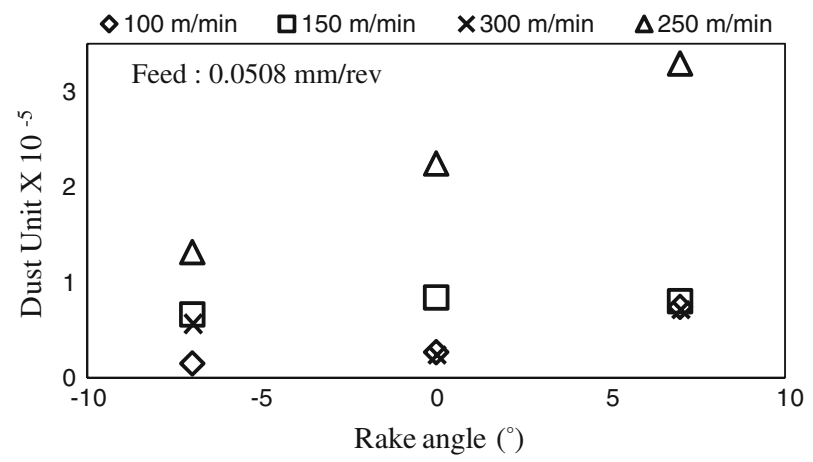

Fig. 6 Dust Unit (PM2.5) as a function of tool rake angle and cutting speeds during turning of 6061-T6 aluminum alloy

Grey cast iron

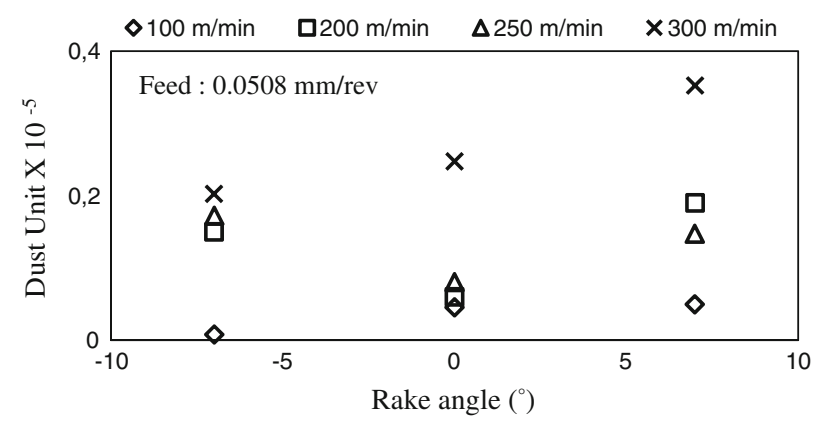

Fig. 7 Dust Unit (PM2.5) as a function of tool rake angle and cutting speeds during turning of gray cast iron

(high cutting speeds), which is the recommended zone, dust emission decreases while the productivity and the part quality are improved, and so high speed machining is not only good for improving productivity and lowering the cutting forces and energy consumption, but also for protecting the environment and worker health.

Gray cast iron, which is a brittle material, presents a special behavior (Fig. 3). In this case, zone III has disappeared and dust emission is continuously increased with the cutting speed. The decrease in dust emission at high speed (zone III) is attributed to the softening effect of ductile materials, and is not the case for brittle materials such as gray cast iron. Khettabi et al. (Ref 30) developed an emissivity factor, called Dust Unit ' $D u$,' which is defined as the ratio between the mass of the dust generated and the mass of the chip produced. This index is highly appropriate for comparing dust emissions resulting from different processes (drilling, turning, and milling) and for performing dust analysis when the machined volume and mass are not equal. In orthogonal cutting at constant depth and length of cut, the dust unit will be the same because for the volume or mass of metal removed, the total dust for a given set of machining parameters is constant. In the following sections, we will use the dust unit $(D u)$ to characterize and analyse dust emissions.

\subsection{Nanoparticles and Size Distribution During Machining}

For a long time, air quality standards were based on particles sized below $10 \mu \mathrm{m}$ (PM10), but this has recently 
been revised downward to PM2.5 (particles with size below $2.5 \mu \mathrm{m}$ ). The results presented so far in this work (Fig. 4-7) were monitored using PM2.5 standards. Though instrument used for this study (a laser photometer "Dustrack") did not allow a measurement of the particle size distribution, it is however not known whether submicronic particles are potentially more dangerous than fine particles, and so it is important to study the generation of submicronic and nanoparticles. An APS coupled with a scanning microscope particle sizer (SMPS) was used to study the particle distribution during orthogonal turning.

It has been found that the deposition of particles less than $0.03 \mu \mathrm{m}$ in size increases as particle diffusivity increases, and that the deposition efficiency increases as compared to a particle with a diameter greater than $0.03 \mu \mathrm{m}$, in which the particle efficiency is less than $10 \%$ (Ref 38). Therefore, nanoparticles present a serious danger to health and to the environment.

During and after the cutting process, analyses of dust generated revealed the presence of a large range of sizes. When analyzing the particle size, it is useful to employ histograms, which aid in visualizing the range and the frequency of the sizes present. According to Reist et al. (Ref 39), for better visualization, the data distribution is spread out by plotting the logarithms of particle diameters on the abscissa instead of the diameters themselves. To maintain the relationship that the area between two particle size intervals is proportional to the total number of particle present, the ordinate scale is obtained as follows:

$y=\frac{\Delta n}{\Delta \log d}$,

where $y$ is the ordinate, $\Delta n$ is the number of particles in each interval, and $\Delta \log d$ is the difference in the logarithms of the largest and the smallest particle sizes of the interval considered. Similar figures are also obtained for particle surface area, particle mass, and volume.

The nanoparticles present a very high sedimentation time due to their small size and the Brownian relaxation time. It is shown in Fig. 8 and 10 that the concentration decreases significantly as particle sizes increase during the cutting of AISI 1018 steel. Most particles generated by machining are nanometric (Fig. 8 and 10), and the effect of the tool rake angle is considerable. Positive rake angles produce more particles than do negative rake angles (Fig. 8-13), confirming the fact that the machining process produces particles of micronic and submicronic sizes. The generation of metallic particles with sizes higher than $10 \mu \mathrm{m}$ is not significant. However, mass concentration, specific surface, and size distribution analyses present a significant concentration of particles of about $250 \mathrm{~nm}$ (Fig. 11 and 12). For micronic sizes, a higher concentration in number and in specific surface was found for particles less than $2 \mu \mathrm{m}$ (Fig. 8 and 10). The size distribution is almost uniform for the mass concentration and is independent of particle sizes (Fig. 9). A high number of nanoparticles per unit volume of air was found for a particle size of about $20 \mathrm{~nm}$ for both negative and positive tool rake angles.

A cutting tool with $\mathrm{a}+7^{\circ}$ rake angle produces more micronic particles (almost double) as does a cutting tool with a negative rake angle $\left(\alpha=-7^{\circ}\right)$. This tendency is observed whatever the number of particles, the mass, or the specific surface involved (Fig. 8-10), with the same behavior observed for nanoparticles (Fig. 11-13).
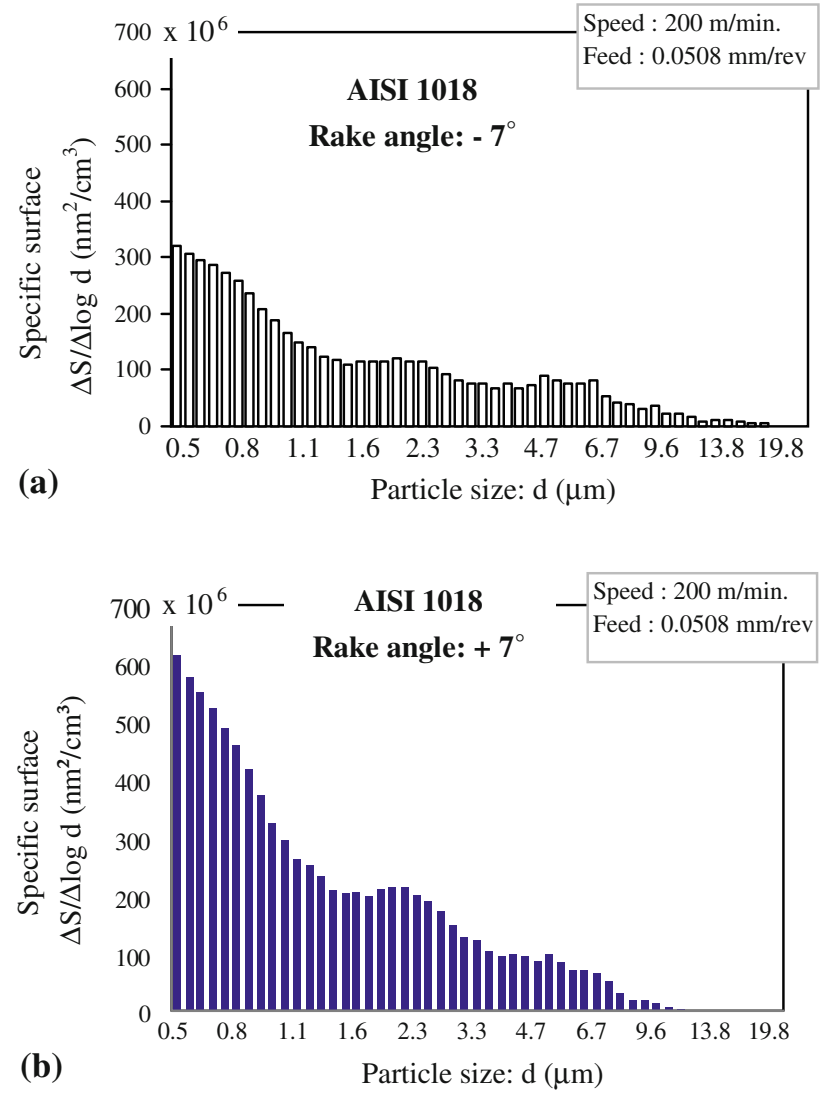

Fig. 8 Effect of the rake angle on the specific surface concentration and the micronic particle size distribution during machining of AISI 1018 steel: (a) negative tool rake angle and (b) positive rake angle
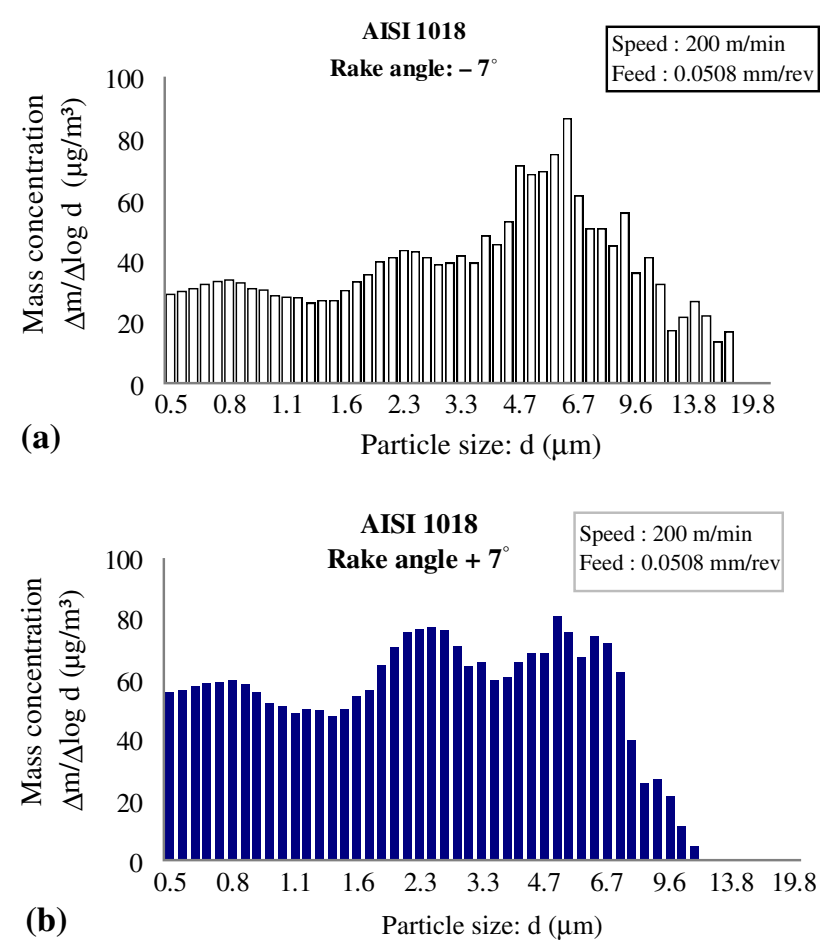

Fig. 9 Effect of the rake angle on the mass concentration and the micronic particle size distribution during machining of AISI 1018 steel: (a) negative tool rake angle and (b) positive rake angle 

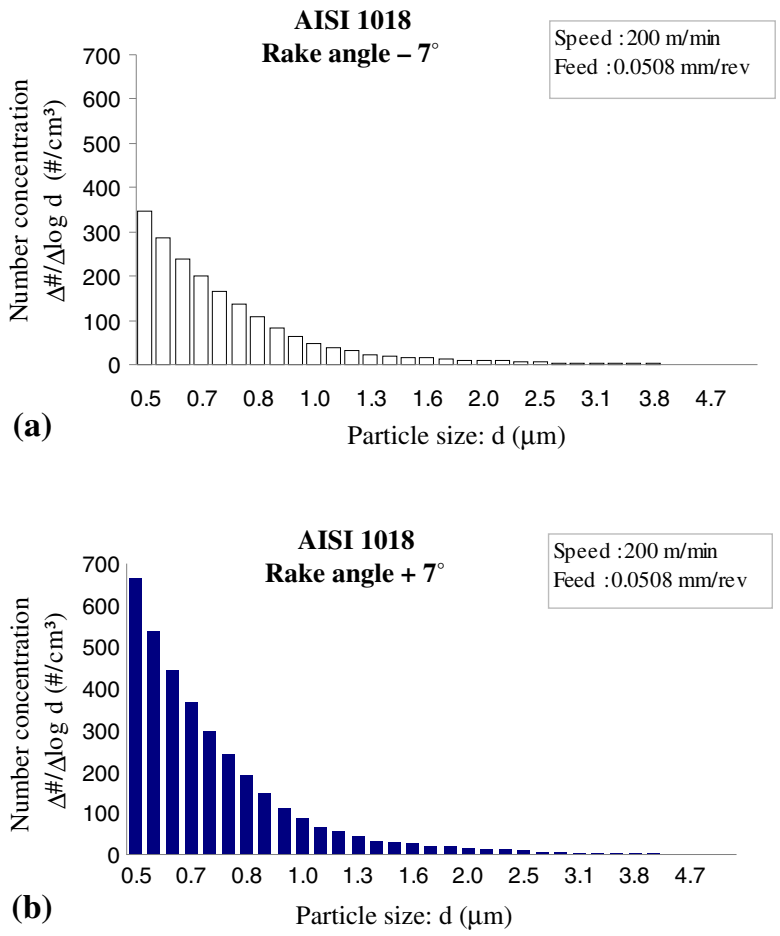

Fig. 10 Effect of the rake angle on the number concentration and the micronic particle size distribution during machining of AISI 1018 steel: (a) negative tool rake angle and (b) positive rake angle
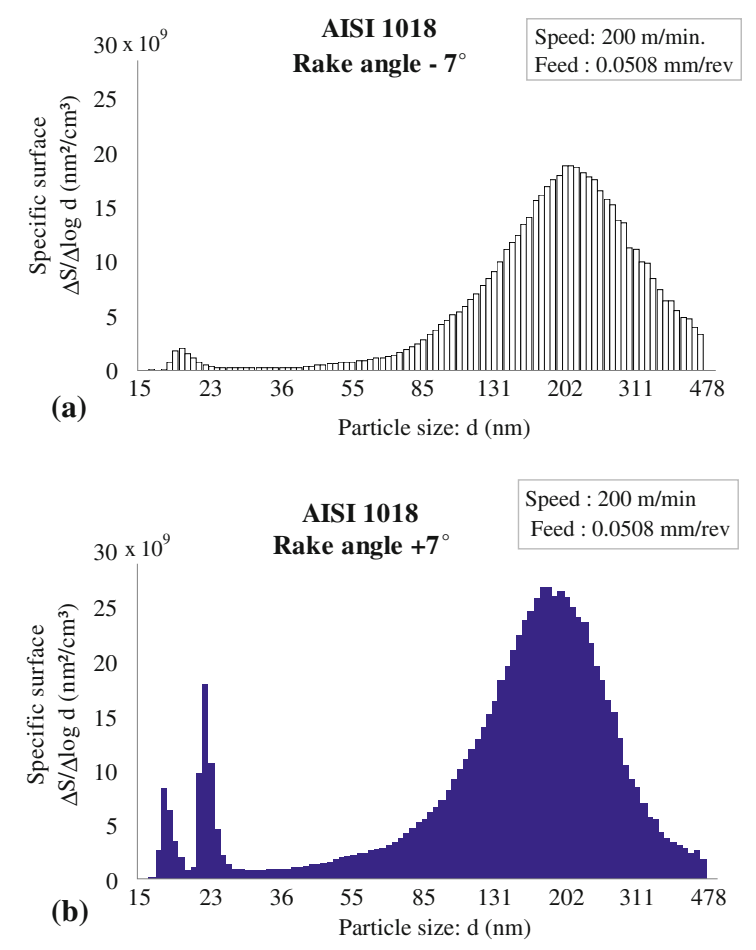

Fig. 11 Effect of the rake angle on the specific surface concentration and the nanometric particle size distribution during machining of AISI 1018 steel: (a) negative tool rake angle and (b) positive rake angle
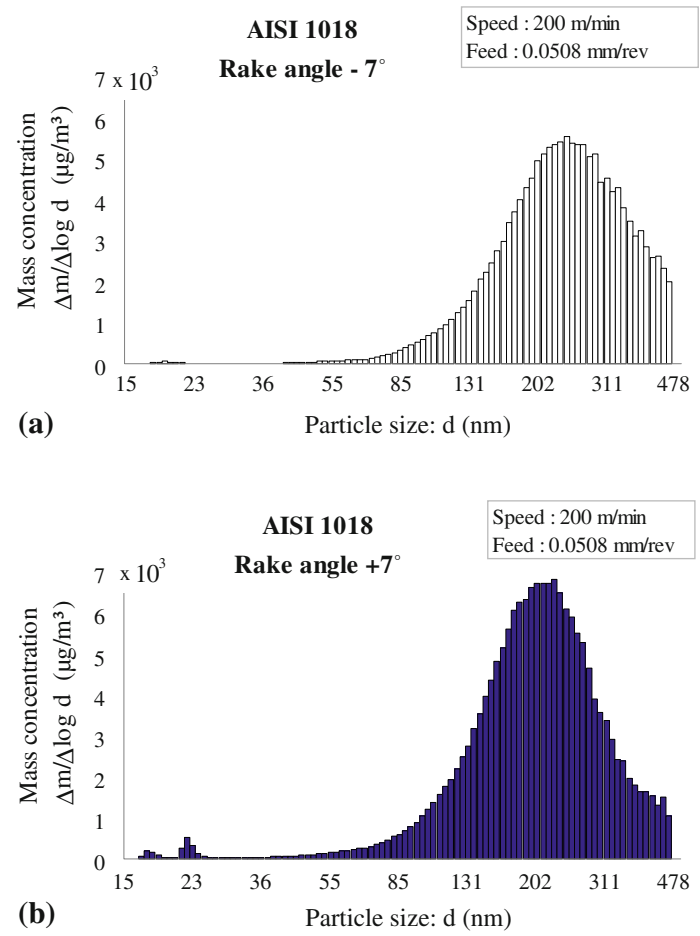

Fig. 12 Effect of the rake angle on the mass concentration and the nanometric particle size distribution during machining of AISI 1018 steel: (a) negative tool rake angle and (b) positive rake angle
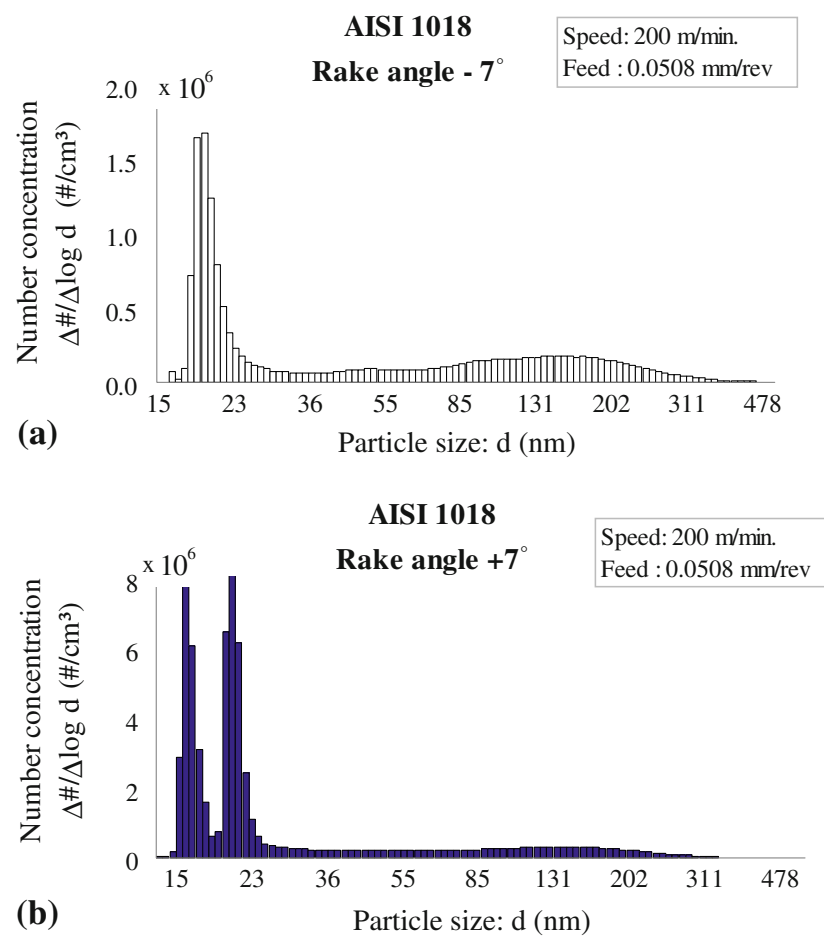

Fig. 13 Effect of the rake angle on the number concentration and the nanometric particle size distribution during machining of AISI 1018 steel: (a) negative tool rake angle and (b) positive rake angle 


\subsection{Chip Formation and Chip Segmentation}

Orthogonal cutting allows a simplification of the cutting process. The chip formation mode is an indication of type of deformation taking place during the cutting process. To study and identify dust formation during machining, we must determine the chip segmentation, the chip ratio, and the chip shape. Figure 14 schematizes the uncut chip cross section in an orthogonal cutting process.

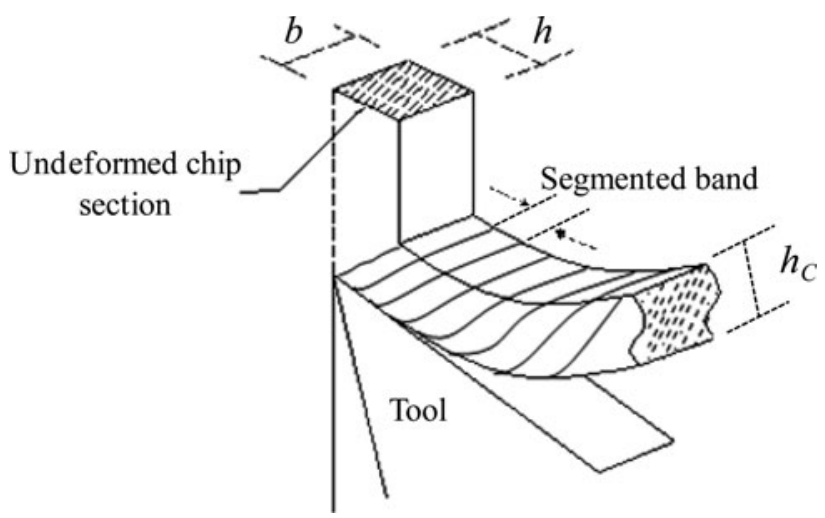

Fig. 14 Orthogonal cutting (uncut chip cross section)
Chip segmentation is an important index that can help to identify the source and mechanisms of dust emission. The segmentation is observed in Table 2, as the chip segmentation increases with the increase in cutting speed and the reduction in the tool rake angle.

In addition, the chip segmentation was defined by Xie et al. (Ref 40) through the introduction of the chip segmentation coefficient $\beta$

$$
\beta=-\frac{\sqrt{3}}{m}\left[\mu+\frac{0.9 \frac{\partial \tau}{\partial T}}{\rho_{\mathrm{p}} C_{\mathrm{p}}\left(1+1.328 B_{0}\right)}\right]\left[\mu \gamma+1-\frac{0.664 B_{0}}{1+1.328 B_{0}}\right],
$$

where $T$ is the temperature, $\rho$ is the workpiece density $(\mathrm{kg} /$ $\left.\mathrm{m}^{3}\right), C_{\mathrm{p}}$ is the workpiece specific heat in $(\mathrm{J} / \mathrm{kg} \mathrm{K}), \mu$ is the average friction coefficient, $\tau$ is the shear stress, and $B_{0}$ is a coefficient defined as follows:

$B_{0}=\sqrt{\frac{K_{\mathrm{p}} \gamma_{\mathrm{AB}}}{V f}}$

where $K_{\mathrm{p}}$ is the workpiece thermal conductivity $(w / m)$ and $\gamma_{\mathrm{AB}}$ is the shear in the primary shear zone. Xie et al. (Ref 40) found that there are some critical values of the product of the cutting speed and feed rate at which the chip segmentation begins. The segmentation can also be defined by

Table 2 Images of aluminum chip segmentation

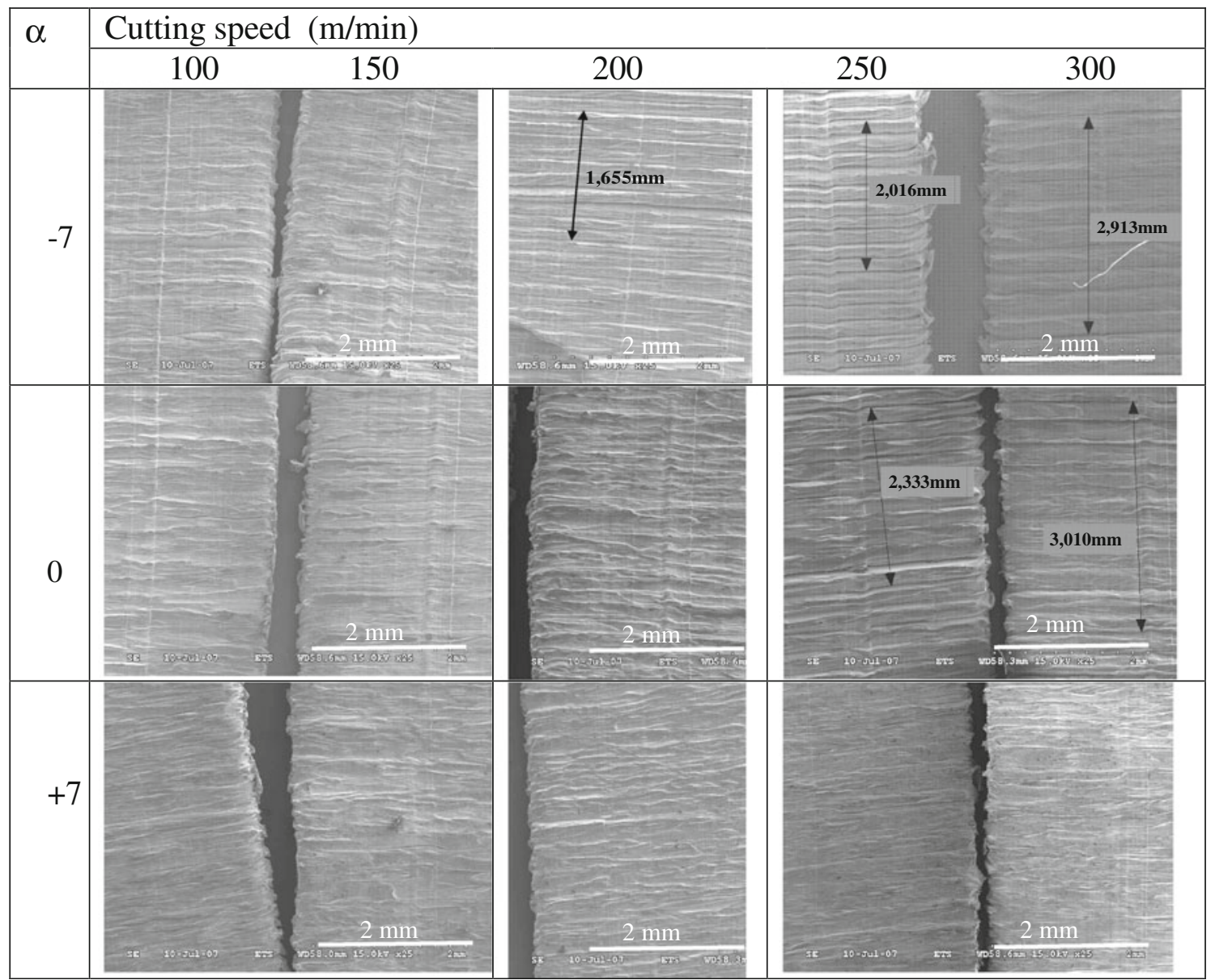


Table 3 Chip segmentation density (6061-T6 aluminum)

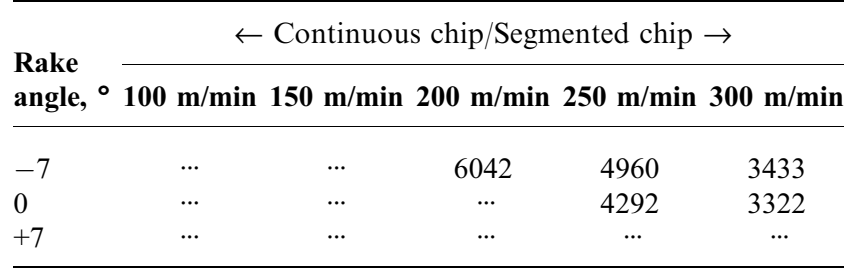

Table 4 Chip ratio (6061-T6 aluminum)

\begin{tabular}{|c|c|c|c|c|c|}
\hline \multirow{2}{*}{$\begin{array}{l}\text { Rake } \\
\text { angle, 。 }\end{array}$} & \multicolumn{5}{|c|}{$\leftarrow$ Thick chip/Thin chip $\rightarrow$} \\
\hline & $100 \mathrm{~m} / \mathrm{min}$ & $150 \mathrm{~m} / \mathrm{min}$ & $200 \mathrm{~m} / \mathrm{min}$ & $250 \mathrm{~m} / \mathrm{min}$ & $300 \mathrm{~m} / \mathrm{min}$ \\
\hline-7 & 0.1876 & 0.1925 & 0.2081 & 0.2199 & 0.2320 \\
\hline 0 & 0.2147 & 0.2027 & 0.2299 & 0.2330 & 0.2387 \\
\hline+7 & 0.2587 & 0.2744 & 0.2593 & 0.2806 & 0.2894 \\
\hline
\end{tabular}

the segmentation band density. The measurement is carried out with special SEM software. Let $l$ be a distance corresponding to 10 segmentation bands; then, the segmentation density $\eta_{\mathrm{s}}$ will be the inverse of the bandwidth:

$\eta_{\mathrm{S}}=\frac{1}{l_{\mathrm{b}}}=\frac{10}{l}$

where $l_{\mathrm{b}}$ is the bandwidth.

For the aluminum alloy 6061-T6 cut with a -7 rake angle, the segmentation is observable at speeds starting at $200 \mathrm{~m} / \mathrm{min}$, while for the null rake angle, observable chip segmentation starts at about $250 \mathrm{~m} / \mathrm{min}$, and for a $+7^{\circ}$ rake angle, there is no noticeable segmentation. In the absence of noticeable chip segmentation, the chip is continuous, whereas it is partially or completely segmented when segments are visible. These results are summarized in Table 3.

The chip compression ratio is presented in Table 4 in the same format as in Table 3. In both tables (Table 3 and 4), the empty boxes represent a continuous chip formation zone. The chip compression ratio $C_{h}$ can be calculated as follows:

$C_{h}=\frac{\sin \phi}{\cos (\phi-\alpha)}$

where $a$ is the tool rake angle and $\phi$ is the shear angle, which can be measured or calculated by the Zvorykin formula (Eq 6):

$\phi=A+\frac{\alpha-\lambda}{2}$

The chip compression ratio can also be geometrically measured by:

$C_{h}=\frac{h}{h_{\mathrm{c}}}$

where $h$ is the undeformed chip thickness and $h_{\mathrm{c}}$ is the chip thickness.

In Table 4, the chip compression ratio is measured geometrically for the aluminum alloy 6061-T6. When the cutting speed increases, the chip compression ratio increases, and the chip becomes thin and brittle, and when this happens the dust emission rate decreases significantly.
There is a correlation between chip morphology, cutting parameters, and dust emission. Continuous chips produce more dust than segmented chips, while an increase in the segmentation density increases dust emission. In Table 3, the density of segmentation drops from a certain value of cutting speed, depending on the tool geometry. However, the negative tool rake angle produces more brittle and segmented chips than does the positive tool rake angle (Table 3 and 4), and therefore, the decrease in the tool rake angle increases the brittleness of the chip during machining. For a positive tool rake angle, the deformation is less than that obtained with the negative tool rake angle, but the contact length is also greater in the positive rake angle. Consequently, dust emission increases as the tool rake angle increases (Fig. 4-13).

The size distribution analysis presents the same behavior regarding the effects of the tool rake angle, cutting speed, and materials. For nanoparticles and different concentrations, the negative tool rake angle produces less nanometric dust than does a positive rake angle under the same conditions.

\section{Conclusion}

In this work, the influence of tool geometry on dust emission was studied. It was shown that a $-7^{\circ}$ tool rake angle generates less dust than $\mathrm{a}+7^{\circ}$ rake angle because of a higher degree of chip segmentation when using lower tool rake angle. In order to reduce dust emissions even further, a null or negative rake angle is recommended; however, it would seem that the null rake angle is optimal for obtaining less chip deformation (minimum cutting load) and minimum dust emission. The material used has a significant impact on dust emission; specifically, the brittleness of the chip plays an important role. There are three different ranges of cutting speeds for which dust emissions are different, with the presence of the third being a characteristic of ductile materials. Dust emission increases with cutting speeds for brittle materials, but the quantity of particle emission remains generally very small when compared to the situation with ductile materials.

Experimental results show that most particles generated (number) during machining are nanoparticles of about $20 \mathrm{~nm}$ in aerodynamic diameter. In future works, an analytical model will be developed to predict dust emission levels, taking into account the effects of cutting parameters, workpiece material, tool geometry, and particle size distribution.

\section{Acknowledgments}

The authors thank ALCAN and the Natural Sciences and Engineering Research Council of Canada (NSERC) for financial support, and the graduate student, G. D'Amours, for the help provided during the machining tests.

\section{References}

1. N.R. Dhar and M.W. Islam, The Influence of Minimum Quantity of Lubrication (MQL) on Cutting Temperature, Chip and Dimensional Accuracy in Turning AISI-1040 Steel, J. Mater. Process. Technol., 2006, 171(1), p 93-99

2. N.R. Dhar, M. Kamruzzaman, and M. Ahmed, Effect of Minimum Quantity Lubrication (MQL) on Tool Wear and Surface Roughness in 
Turning AISI-4340 Steel, J. Mater. Process. Technol., 2006, 172, p 299-304

3. Y. Yue, K.L. Gunter, D.J. Michalek, and J.W. Sutherland, Cutting Fluid Mist Formation in Turning Via Atomization Part 1: Model Development, IMECE Proc. of ASME: Manufacturing Engineering Division, ASME Bound Volume-MED, 2000, Vol 11, p 843-850

4. Y. Yue, K.L. Gunter, D.J. Michalek, and J.W Sutherland, Cutting Fluid Mist Formation in Turning Via Atomization. Part 2: Experimental Validation, IMECE Proc. of ASME: Manufacturing Engineering Division, ASME Bound Volume-MED, 2000, Vol 11, p 851-858

5. Y. Yue, J. Sun, K.L. Gunter, D.J. Michalek, and J.W. Sutherland, Character and Behaviour of Mist Generated by Application of Cutting Fluid to a Rotating Cylindrical Work Piece, Part 1: Model Development, J. Manuf. Sci. Eng. Trans. ASME, 2004, 126(3), p 417-425

6. D.D. Bell, J. Chou, L. Nowag, and S.Y. Liang, Modeling of the Environmental Effect of Cutting Fluid, Tribol. Trans., 1999, 42(1), p 168-173

7. D. Chen, M. Sarumi, and S.T.S. Al-Hassani, Computational Mean Particle Erosion Model, Wear, 1998, 214, p 64-73

8. Z. Chen, A. Atmadi, D.A. Stephenson, and S.Y. Liang, Analysis of Cutting Fluid Aerosol Generation for Environmentally Responsible Machining, CIRP Ann. Manuf. Technol., 2000, 49(1), p 53-56

9. Z. Chen, S.Y. Liang, and H. Yamaguchi, Predictive Modeling of Cutting Fluid Aerosol Generation in Cylindrical Grinding, NAMRC, May 21-24 2002 (West Lafayette, ID), Society of Manufacturing Engineers, $\mathrm{p} 1-8$

10. Z. Chen, K. Wong, W. Li, D.A. Stephenson, and S.Y. Liang, Cutting Fluid Aerosol Generation Due to Spin-Off in Turning Operation: Analysis for Environmentally Conscious Machining, Manufacturing Science and Engineering - 1999 (The ASME International Mechanical Engineering Congress and Exhibition), Nov 14-Nov 19, 1999

11. A. Atmadi, D.A. Stephenson, and S.Y. Liang, Cutting Fluid Aerosol from Splash in Turning: Analysis for Environmentally Conscious Machining, Int. J. Adv. Manuf. Technol., 2001, 17(4), p 238-243

12. H.W. Rossmoore and L.A. Rossmoore, Effect of Microbial Growth Products on Biocide Activity in Metalworking Fluids, Symposium on Extra cellular Microbial Products in Bio-deterioration, Apr 9-10, 1990, Int. Bio-deteriorat., 27(2), p 145-156

13. M. Sondossi, H.W. Rossmoore, and R. Williams, Relative Formaldehyde Resistance Among Bacterial Survivors of Biocide-Treated Metalworking Fluid, Int. Bio-deteriorat. Biodegrad., 2001, 48(1-4), p 286-300

14. J.W. Sutherland, V.N. Kulur, and N.C. King, Experimental Investigation of Air Quality in Wet and Dry Turning, CIRP Ann. Manuf. Technol., 2000, 49(1), p 61-64

15. WHO, Hazard Prevention and Control in the Work Environment: Airborne Dust, Prevention and Control Exchange (PACE), World Health Organization, WHO/SDE/OEH/99.14, Geneva, Switzerland, 1999, p 1-219

16. H.K. Tönshoff, B. Karpuschewski, and T. Glatzel, Particle Emission and Immission in Dry Grinding, Ann. CIRP, 1997, 46(2), p 693-695

17. R.B. Aronson, Why Dry Machining?, Manuf. Eng., 1999, 114(1), p 33-36

18. B. Corzine, OSHA's Proposed Chromium PEL and The Problem of Sampling Source, Plating Surface Finish, 2005, 92(6), p 6-7

19. D. Dudzinski, A. Devillez, A. Moufki, D. Larrouquere, V. Zerrouki, and J. Vigneau, A Review of Developments Towards Dry and High Speed Machining of Inconel 718 Alloy, Int. J. Mach. Tool. Manufact., 2004, 44, p 439-456

20. K. Weinert, Relation Between Process Energy and Tool Wear When Turning Hard Facing Alloys, CIRP Ann. Manufact. Technol., 1994, 43(1), p 97-100
21. K.I. Weinert, J.W. Sutherland, and T. Wakabayashi, Dry Machining and Minimum Quantity Lubrication, CIRP Ann. Manufact. Technol., 2004, $\mathbf{5 3}(2)$, p 511-537

22. J. McCabe and M.A. Ostraff, Performance Experience with Near-Dry Machining of Aluminium, Lubricat. Eng., 2001, 57(12), p 22-27

23. T. Makiyama, Developments in Machine Tools for MQL Cutting, Toraibarojisuto/J. Jpn Soc. Tribol., 2002, 47(7), p 533

24. T. Makiyama and Y. Yamane, Drilling with MQL Process. Progress of Machining Technology, Proceedings of the Seventh International Conference on Progress Machining Technology, ICPMT2004, Dec 811 2004, Suzhou, China, Aviation Industry Press, Anwai, Beijing, 100029, China, p 232-236

25. S. Suda, Developments in Cutting Fluids for MQL Cutting, Toraibarojisuto/J. Jpn Soc. Tribol., 2002, 47(7), p 550

26. T. Wakabayashi, I. Inasaki, and S. Suda, Tribological Action and Optimal Performance: Research Activities Regarding MQL Machining Fluids, Mach. Sci. Technol., 2006, 10(1), p 59-85

27. B. Balout, V. Songmene, and J. Masounave, Usinabilité des alliages de magnésium et d'aluminium Partie I: Forces de coupe. Proc. of the International Symposium on Enabling Technologies for Light Metal and Composite Materials and Their End-Products, 4lth Conf. of Metallurgists of CIM, 2002, p 223-242

28. V. Songmene, B. Balout, and J. Masounave, Clean Machining: Experimental Investigation on Dust Formation-Part I: Influence of Machining Parameters and Chip Formation, Int. J. Environ. Conscious Des. Manuf. (ECDM), 2008, 14, p 1-16

29. V. Songmene, B. Balout, and J. Masounave, Clean Machining: Experimental Investigation on Dust Formation - Part II: Influence of Machining Strategies and Drill Condition, Int. J. Environ. Conscious Des. Manuf. (ECDM), 2008, 14, p 17-33

30. R. Khettabi, V. Songmene, and J. Masounave, Effect of Tool Lead Angle and Chip Formation Mode on Dust Emission in Dry Cutting, J. Mater. Process. Technol., 2007, 194(1-3), p 100-109

31. Y. Ohbuchi and T. Obikawa, Finite Element Modelling of Chip Formation in the Domain of Negative Rake Angle Cutting, J. Eng. Mater. Technol. Trans. ASME, 2003, 125, p 324-332

32. N. Fang, Tool-Chip Friction in Machining with a Large Negative Rake Angle Tool, Wear, 2005, 258, p 890-897

33. P. Dahlman, F. Gunnberg, and M. Jacobson, The Influence of Rake Angle, Cutting Feed and Cutting Depth on Residual Stresses in Hard Turning, Mater. Process. Technol., 2004, 147, p 181-184

34. T.M. Peters, O. Darrin, and P.T. O'Shaughnessy, Comparison of the Grimm 1.108 and 1.109 Portable Aerosol Spectrometer to the TSI, 3321 Aerodynamic Particle Sizer for Dry Particles, Ann. Occup. Hyg., 2006, 50, p 843-850

35. P.U. Arumugam, A.P. Malshe, and S.A. Batzer, Dry Machining of Aluminium-Silicon Alloy Using Polished CVD Diamond-Coated Cutting Tools Inserts, Surf. Coat. Technol., 2006, 200(11), p 3399-3403

36. R. Tourret, Performance of Metal-Cutting Tools, Butter Works Publication Limited, Great Britain, 1958

37. G. Boothroyd, Knight, Fundamentals of Machining and Machine Tools, 3rd ed., Taylor \& Francis, London, New York, 2006

38. J.T. Kelly, A. Bahman, J.S. Kimbell, and B.A. Wong, Particle Deposition in Human Nasal Airway Replicas Manufactured by Different Methods Part II: Ultrafine Particles, Aerosol. Sci. Technol., 2004, 38, p 1072-1079

39. P.C. Reist, Aerosol Science and Technology, 2nd ed., Mc Graw-Hill Inc, New York, 1993

40. J.Q. Xie, A.E. Bayoumi, and H.M. Zbib, Study on Shear Banding in Chip Formation of Orthogonal Machining, Int. J. Mach. Tool. Manufact., 1996, 36(7), p 835-847 